\title{
GROWTH AND MARKETABLE POTATO (SOLANUM TUBEROSUM L.) TUBER YIELD IN RESPONSE TO FOLIAR APPLICATION OF SEAWEED EXTRACT AND HUMIC ACIDS
}

\author{
WADAS, W. $.^{*}-$ DZIUGIEL, T. ${ }^{2}$ \\ ${ }^{I}$ Department of Vegetable Crops, Faculty of Natural Sciences, Siedlce University of Natural \\ Sciences and Humanities, B. Prusa 14, 08-110 Siedlce, Poland
}

${ }^{2}$ Voivodeship Plant Health and Seed Inspection Service, Main Inspectorate of Plant Health and Seed Inspection, Żótkiewskiego 17, 05-075 Warszawa-Wesoła, Poland

*Corresponding author

e-mail: wanda.wadas@uph.edu.pl; phone: +48-25-643-1296

(Received $3^{\text {rd }}$ Jun 2019; accepted $2^{\text {nd }}$ Sep 2019)

\begin{abstract}
The effect of foliar application of seaweed extracts Bio-algeen S90 (Ascophyllun nodosum) and Kelpak SL (Ecklonia maxina) and humic and fulvic acids from leonardite HumiPlant on plant growth and marketable tuber yield of early potato crop was investigated. The application of seaweed extracts resulted in a faster rate of plant growth. Bio-algeen S90 affected potato growth more than Kelpak SL. The plants grew taller and produced a greater above-ground biomass. With the use of HumiPlant, stems were shorter but had a similar weight to plants in the cultivation without biostimulant. Biostimulants caused enlargement of the assimilation leaf area, but had no effect on the weight of leaves, leaf weight ratio (LWR) or leaf area ratio (LAR). The yield-increasing effect of biostimulants depended on hydrothermal conditions during potato growth. Seaweed extracts produced better results in a warm and a very wet growing season, whereas humic and fulvic acids produced better results in a cool growing season with drought during the tuber growth period.
\end{abstract}

Keywords: biostimulant, plant height, above-ground biomass, assimilation leaf area, leaf area ratio (LAR), leaf weight ratio (LWR)

\section{Introduction}

Potato (Solanum tuberosum L.) growth and, as a result, tuber yield depends on the site-specific interaction between cultivar and environment, and on the agronomic practices. Potato growth is influenced by many biotic and abiotic stress factors. In sustainable agriculture, biostimulants have been gaining increasing importance. Biostimulants contain a wide range of bioactive compounds that increase plant stress resistance, which allows better use of the cultivar production potential under the environmental conditions of the cultivar area (Calvo et al., 2014; Bulgari et al., 2015). In field crop production, the most commonly used are seaweed extracts and humic acids (Battacharyya et al., 2015; Canellas et al., 2015).

Many plant growth-stimulating compounds such as auxins, cytokinins, gibberellins, betaines, polyamines, abscisic acid, brassinosteroids and minerals were identified from seaweed. These compounds affect cellular metabolism in treated plants, leading to increased tolerance to abiotic stresses, improved plant growth and crop yield (Craige, 2011; Sharma et al., 2014). Most commercial seaweed products are manufactured from red (Lithothamnium calcareum) and brown (Ascophyllum nodosum, Ecklonia maxima, Sargassum spp., and Durvillaea spp.) microalgae (Craige, 2011). The plant growthpromoting effects of seaweed extracts have been documented in several agricultural and horticultural crops such as tomato, onion, pepper, carrot, potato, wheat, barley and 
maize. Seaweed extract applied via roots or leaves stimulates plant growth in a speciesspecific manner. The effect of seaweed extract on plant growth depends on the date and dose of application (Haider et al., 2012; Sharma et al., 2014; Begum et al., 2018).

A study carried out in Finland showed that in long-day conditions characterized by a cool and short growing season, the foliar application of the first seaweed extract SM3 (originally called Sea Magic) had a remarkable effect on potato growth and tuber yield (Kuisma, 1989), whereas a later study carried out in Iraq showed that the foliar application of extracts from brown seaweed Sargassum Alga 600 and Sea force 2 promoted potato growth and increased tuber yield (Sarhan, 2011). A positive response of potato plant growth and yield to the foliar application of the extracts from Ascophyllum nodosum (Primo, Bio-algeen S90) and Ecklonia maxima (Keplak SL) was shown in studies carried out in Pakistan and Poland (Haider et al., 2012; Wierzbowska et al., 2015) and the extracts from Kappaphycus alvarezii (K sap) and Gracilaria edulis (G sap) in a study carried out in India (Prajapati et al., 2016).

Humic substances are able to produce positive effect on the growth, yield and quality of potato (Verlinden et al., 2009). The biostimulant effects of humic substances extracted from naturally humified organic matter, from composts, or from mineral deposition are characterized by both structural and physiological changes in plants. The activity of humic substances is related to their chemical structure (Calvo et al., 2014; Canellas et al., 2015). Humic acids have been reported to stimulate the growth of such crops as wheat, rice, maize, tomato, cucumber, pepper and potato. The effect of humic acids on plant growth depends on their source and concentration and on the date and method (foliar or soil) of application, as well as the plant species (Calvo et al., 2014; Canellas et al., 2015; Alenazi et al., 2016; Zhang et al., 2017). A strong potato response to the application of humic substances originating from leonardite formations in Canada has been reported (Verlinden et al., 2009). Later studies carried out in Poland, Saudi Arabia and China confirmed the positive effect of humic and fulvic acids on potato growth and on tuber yield and quality (Matysiak and Adamczewski, 2010; Alenazi et al., 2016; Zhang et al., 2017). The results of a study carried out in Korea showed that foliar or soil application of fulvic and humic acids had no clear promotional effects on tuber growth or potato yield (Suh et al., 2014).

The application of humic substances (soluble humic and fulvic acids fractions) and seaweed extracts shows inconsistent, yet a generally positive, effect on plant growth. To date, few studies have been focused on the effects of seaweed extracts and humic acids application on early crop potato culture. In our study it was hypothesised that the stimulation of potato plant growth by seaweed extracts and humic acid application would contribute to increase early potato crops. The assumption was also made that the potato response to foliar application of seaweed extracts and humic acids depends on the potato cultivar and environmental conditions. The aim of the study was to determine the effect of seaweed extracts and humic acid application on plant growth and marketable tuber yield of very early potato cultivars.

\section{Materials and methods}

\section{Experimental site and season}

The field experiment was carried out in central-eastern Poland - 52 $03^{\circ} \mathrm{N}, 22^{\circ} 33^{\prime} \mathrm{E}$ (Fig. 1) during three growing season of the 2012-2014 period, on loamy soil (Luvisol) with an acidic-to-slightly-acid reaction ( $\mathrm{pH}$ in $1 \mathrm{M} \mathrm{KCl}$ from 4.7 to 6.3). The content of 
available phosphorus in the soil ranged from 118 to $144 \mathrm{mg} \mathrm{P} \mathrm{kg}^{-1}$, potassium from 124 to $208 \mathrm{mg} \mathrm{K} \mathrm{ha}^{-1}$ and magnesium from 22 to $51 \mathrm{mg} \mathrm{Mg} \mathrm{kg}^{-1}$ of soil. In each year of the study, spring triticale was grown as a potato forecrop. Farmyard manure was applied in autumn, at rate of $25 \mathrm{t} \mathrm{ha}^{-1}$, and mineral fertilizers were applied in rates $80 \mathrm{~kg} \mathrm{~N}$ (ammonium nitrate), $35 \mathrm{~kg} \mathrm{P}$ (superphosphate) and $100 \mathrm{~kg} \mathrm{~K}$ (potassium sulphate) per hectare in spring. Potato cultivation was carried out according to common agronomical practice. Colorado potato beetle (Leptinotarsa decemlineata) was controlled using Actara $25 \mathrm{WG}$ (thiametoksam) and Apacz $50 \mathrm{WG}$ (chlotianidine).

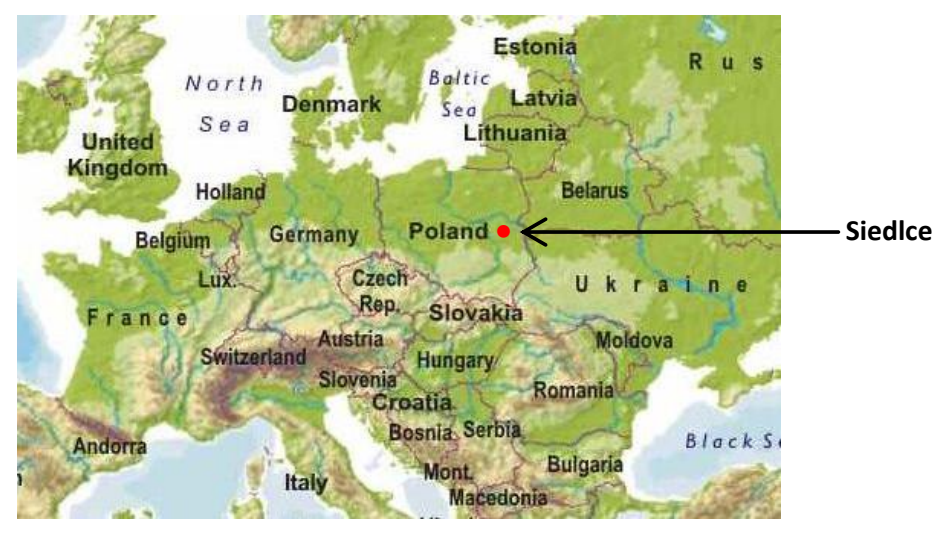

Figure 1. Location of experimental site (http://freeworldmaps.net)

\section{Plant material and experimental design}

The field experiment was established in the split-plot design with three replications. The experimental factors were as follows: (i) - type of biostimulant: control treatment without biostimulant, Bio-algeen S90 - $2 \mathrm{~L} \mathrm{ha}^{-1}$ at the beginning of leaf development stage BBCH 10-11 and $2 \mathrm{~L} \mathrm{ha}^{-1}$ after two weeks from first treatment, Kelpak SL $2 \mathrm{~L} \mathrm{ha}^{-1}$ at the leaf development stage BBCH 14-16 and $2 \mathrm{~L} \mathrm{ha}^{-1}$ after two weeks from first treatment, HumiPlant $-2 \mathrm{~L} \mathrm{ha}^{-1}$ at the leaf development stage BBCH 14-16 and $2 \mathrm{~L}$ ha $^{-1}$ after one week from first treatment (Table 1); (ii) - potato cultivar: 'Denar', 'Lord', 'Miłek' (Polish cultivars registered on the Common Catalogue of Varieties of Agricultural Plant Species CCV).

Table 1. Characteristics of biostimulants used in the experiment

\begin{tabular}{|c|c|c|}
\hline Trade name & $\begin{array}{c}\text { Source of biologically active } \\
\text { compounds }\end{array}$ & Plant growth-stimulating compounds \\
\hline Bio-algeen S90 & $\begin{array}{c}\text { Seaweed extract } \\
\text { Ascophyllum nodosum }\end{array}$ & $\begin{array}{c}90 \text { groups of chemical compounds including: } \\
\text { amino acids, vitamins, alginic acid and other active } \\
\text { components of seaweeds, } \mathrm{N}-0.02 \%, \mathrm{P}-0,006 \% \text {, } \\
\mathrm{K}-0,096 \%, \mathrm{Ca}-0,31 \%, \mathrm{Mg}-0,021 \%, \mathrm{~B}-16 \mathrm{mg} \mathrm{kg}^{-1} \text {, } \\
\mathrm{Fe}-6,3 \mathrm{mg} \mathrm{kg}-\mathrm{Cu}-0,2 \mathrm{mg} \mathrm{kg} \mathrm{gn}^{-1}, \mathrm{Mn}-0,6 \mathrm{mg} \mathrm{kg}^{-1}, \\
\mathrm{Zn}-1,0 \mathrm{mg} \mathrm{kg}{ }^{-1}, \mathrm{Mo}, \mathrm{Se}, \mathrm{Co}\end{array}$ \\
\hline Kelpak SL & $\begin{array}{l}\text { Seaweed extract } \\
\text { Ecklonia maxima }\end{array}$ & Auxin - $11 \mathrm{mg} \mathrm{L}$, cytokinin - $0.031 \mathrm{mg} \mathrm{L}$ \\
\hline HumiPlant & Leonardite extract & $\begin{array}{l}\text { Humic acid - } 12 \% \text {, fulvic acid - } 6 \% \text {, } \\
\mathrm{K}_{2} \mathrm{O}-3 \%, \mathrm{Fe}, \mathrm{Ca}, \mathrm{Mn}, \mathrm{S}, \mathrm{Mg}, \mathrm{B}, \mathrm{Mo}, \mathrm{Zn}, \mathrm{Cu}\end{array}$ \\
\hline
\end{tabular}


In successive years, 6-weeks pre-sprouted seed potatoes were planted on the $12^{\text {th }}$, $18^{\text {th }}$ and $7^{\text {th }}$ and 4 April, with an in-row spacing of $25 \mathrm{~cm}$ and $67.5 \mathrm{~cm}$ between rows. The average length of sprouts at the time of planting was $15-20 \mathrm{~mm}$. The plots were six rows wide and $4 \mathrm{~m}$ long (96 plants per plot). At the tuber formation stage (BBCH 41 43), the length and weight of stems and weight of leaves and assimilation leaf area were determined. The measurements were made on four successive plants per plot. The assimilation leaf area was measured by the weight method based on the weight of pieces with a known diameter and total weight of leaves per plant (Wadas and Kalinowski, 2017). The leaf weight ratio (LWR) and leaf area ratio (LAR) were calculated. LWR and LAR were calculated as the ratio of the weight of leaves/weight of the whole plant and the ratio of assimilation leaf area/weight of the whole plant, respectively (Pietkiewicz, 1985). Potatoes were harvested 75 days after planting (the end of June). The marketable tuber yield (diameter above $30 \mathrm{~mm}$ ) was determined.

\section{Statistical analysis}

The results of a two-way field experiment were analysed statistically by means of analysis of variance (ANOVA) for the split-plot design. The significance of differences was verified using Tukey's test at $\mathrm{p} \leq 0.05$ (Table 2).

Table 2. Effect of experimental factors on potato growth and tuber yield

\begin{tabular}{c|c|c|c|c|c|c|c}
\hline $\begin{array}{c}\text { Experimental } \\
\text { factors }\end{array}$ & $\begin{array}{c}\text { Length of } \\
\text { stems }\end{array}$ & $\begin{array}{c}\text { Weight of } \\
\text { stems }\end{array}$ & $\begin{array}{c}\text { Leaf } \\
\text { area }\end{array}$ & $\begin{array}{c}\text { Weight of } \\
\text { leaves }\end{array}$ & $\begin{array}{c}\text { Leaf weight } \\
\text { ratio (LWR) }\end{array}$ & $\begin{array}{c}\text { Leaf area } \\
\text { ratio (LAR) }\end{array}$ & $\begin{array}{c}\text { Tuber } \\
\text { yield }\end{array}$ \\
\hline Year (Y) & $* *$ & $* *$ & $* *$ & $* *$ & $* *$ & $* *$ & $* *$ \\
Biostimulant (B) & $* *$ & $* *$ & $* *$ & $\mathrm{~ns}$ & $\mathrm{~ns}$ & $\mathrm{~ns}$ & $*$ \\
$\mathrm{Y} \times \mathrm{B}$ & $*$ & $* *$ & $* *$ & $\mathrm{~ns}$ & $\mathrm{~ns}$ & $\mathrm{~ns}$ & $*$ \\
Cultivar (C) & $*$ & $* *$ & $* *$ & $*$ & $* *$ & $* *$ & $\mathrm{~ns}$ \\
$\mathrm{Y} \times \mathrm{C}$ & $\mathrm{ns}$ & $* *$ & $* *$ & $\mathrm{~ns}$ & $\mathrm{~ns}$ & $\mathrm{~ns}$ & $* *$ \\
$\mathrm{~B} \times \mathrm{C}$ & $\mathrm{ns}$ & $* *$ & $* *$ & $*$ & $\mathrm{~ns}$ & $\mathrm{~ns}$ & $\mathrm{~ns}$ \\
$\mathrm{Y} \times \mathrm{B} \times \mathrm{C}$ & $*$ & $* *$ & $*$ & $\mathrm{~ns}$ & $\mathrm{~ns}$ & $\mathrm{~ns}$ & $\mathrm{~ns}$ \\
\hline
\end{tabular}

*Significant at $\mathrm{p} \leq 0.05, * *$ significant at $\mathrm{p} \geq 0.01$, ns: non-significant

\section{Weather conditions}

The mean air temperatures in the period of potato growth were above or similar to the long-term average (Table 3). In 2012 total precipitation in April-June was similar and in 2013 and 2014 above the long-term average and unevently distributed during potato growth period.

Table 3. Mean air temperature and precipitation total in potato growing period

\begin{tabular}{c|c|c|c|c|c|c}
\hline \multirow{2}{*}{ Years } & \multicolumn{3}{|c|}{ Temperature $\left({ }^{\circ} \mathbf{C}\right)$} & \multicolumn{3}{c}{ Rainfalls (mm) } \\
\cline { 2 - 7 } & April & May & June & April & May & June \\
\hline 2012 & 8.9 & 14.6 & 16.3 & 29.9 & 53.4 & 76.2 \\
2013 & 7.4 & 15.3 & 18.0 & 36.0 & 105.9 & 98.8 \\
2014 & 9.8 & 13.5 & 15.4 & 45.0 & 92.7 & 55.4 \\
Many-year mean (1981-2010) & 8.3 & 12.2 & 16.8 & 41.2 & 53.0 & 63.8 \\
\hline
\end{tabular}


The most favourable thermal and moisture conditions for early crop potato culture were in the warm and moderately wet growing season of 2012. 2013 was warm and with a heavy rainfall, whereas 2014 was cool with a heavy rainfall after the plant emergence and a drought in the period of tuber growth.

\section{Results}

\section{Length and weight of stems}

The type of biostimulant had a significant effect on potato growth (Table 4). Following the application of Bio-algeen S90, the stems were longer by $2.3 \mathrm{~cm}$, on average, and the average weight of stems was $40 \mathrm{~g}$ higher compared with the control object without the growth stimulant. With the application of Kelpak SL the stem lengths were similar and with the application of HumiPlant they were shorter by $3.3 \mathrm{~cm}$, on average, in comparison with the control object, although the stem weights were not significantly different. The effect of tested biostimulants on plant growth depended on weather conditions during the potato growing season. The type of biostimulant had the greatest effect on plant growth in 2014 with a low air temperature and a heavy rainfall after the plant emergence. In that year, after the application of Bio-algeen S90 the weight of stems was higher by $81 \mathrm{~g}$ than the plants from the control object without biostimulant, with a comparable length of stems. Following the application of Keplak SL and HumiPlant, stems were shorter by $3.9 \mathrm{~cm}$ and $5.0 \mathrm{~cm}$, respectively, compared with the plants from the control object with comparable stem weights.

Table 4. Length and weight of stems

\begin{tabular}{c|c|c|c|c|c|c|c|c}
\hline \multirow{2}{*}{ Type of biostimulant } & \multicolumn{7}{c|}{ Years } & \multicolumn{3}{c}{ Cultivar } & \multirow{2}{*}{ Mean } \\
\cline { 2 - 7 } & $\mathbf{2 0 1 2}$ & $\mathbf{2 0 1 3}$ & $\mathbf{2 0 1 4}$ & Denar & Lord & Miłek & \\
\hline \multicolumn{7}{c}{ Length of stems (cm) } \\
\hline Without biostimulant & $63.6 \mathrm{~b}$ & $59.0 \mathrm{ab}$ & $82.5 \mathrm{a}$ & 72.1 & 71.8 & 61.2 & $68.4 \mathrm{~b}$ \\
Bio-algeen S90 & $67.6 \mathrm{a}$ & $59.7 \mathrm{a}$ & $84.8 \mathrm{a}$ & 76.5 & 77.0 & 58.7 & $70.7 \mathrm{a}$ \\
Kelpak SL & $67.4 \mathrm{a}$ & $56.8 \mathrm{ab}$ & $78.6 \mathrm{~b}$ & 74.3 & 72.6 & 55.9 & $67.6 \mathrm{~b}$ \\
HumiPlant & $61.8 \mathrm{~b}$ & $55.9 \mathrm{~b}$ & $77.5 \mathrm{~b}$ & 71.2 & 70.1 & 54.1 & $65.1 \mathrm{c}$ \\
Mean & $65.1 \mathrm{~B}$ & $57.9 \mathrm{C}$ & $80.9 \mathrm{~A}$ & $73.5 \mathrm{~A}$ & $72.9 \mathrm{~A}$ & $57.5 \mathrm{~B}$ & \\
\hline \multicolumn{7}{c}{ Weight of stems (g) } \\
\hline Without biostimulant & $306 \mathrm{a}$ & $208 \mathrm{a}$ & $475 \mathrm{~b}$ & $371 \mathrm{~b}$ & $311 \mathrm{~b}$ & $308 \mathrm{a}$ & $330 \mathrm{~b}$ \\
Bio-algeen S90 & $328 \mathrm{a}$ & $225 \mathrm{a}$ & $556 \mathrm{a}$ & $434 \mathrm{a}$ & $396 \mathrm{a}$ & $280 \mathrm{ab}$ & $370 \mathrm{a}$ \\
Kelpak SL & $350 \mathrm{a}$ & $189 \mathrm{a}$ & $451 \mathrm{~b}$ & $374 \mathrm{~b}$ & $369 \mathrm{a}$ & $247 \mathrm{~b}$ & $330 \mathrm{a}$ \\
HumiPlant & $313 \mathrm{a}$ & $183 \mathrm{a}$ & $451 \mathrm{~b}$ & $364 \mathrm{~b}$ & $318 \mathrm{~b}$ & $264 \mathrm{ab}$ & $315 \mathrm{~b}$ \\
Mean & $324 \mathrm{~B}$ & $201 \mathrm{C}$ & $483 \mathrm{~A}$ & $386 \mathrm{~A}$ & $348 \mathrm{~A}$ & $348 \mathrm{~A}$ & \\
\hline
\end{tabular}

Means within columns/rows followed by the same lowercase/uppercase letters do not differ significantly at $\mathrm{p} \leq 0.05$

The type of biostimulant and cultivar interaction effect on the length of stems was not statistically confirmed. Bio-algeen S90 had a greater effect on the weight of stems of 'Denar' and 'Lord' than 'Miłek' (Table 4). The differences were highest in 2014 with a low air temperature and a heavy rainfall after plant emergence. 
The rate of plant growth depended on the cultivar and weather conditions (Table 4). Regardless of the treatment (with or without biostimulant), the length and weight of stems were higher for 'Denar' and 'Lord' than for 'Miłek'. The stems were longest and they had the greatest weight in 2014, with the highest air temperature and moderate rainfall in the second half of May.

\section{Weight of leaves and assimilation leaf area}

The biostimulants used in the experiment had no significant effect on the weight of leaves, but caused enlargement of the assimilation leaf area, on average, by $366 \mathrm{~cm}^{2}$ to $664 \mathrm{~cm}^{2}$ (Table 5). The type of biostimulant and year interaction effect on the assimilation leaf area was statistically confirmed. In 2013 with the highest air temperature and a heavy rainfall after plant emergence, the greatest enlargement of assimilation leaf area, on average by $624 \mathrm{~cm}^{2}$, was caused by Kelpak SL. In 2014 with the lowest air temperature and a heavy rainfall after plant emergence, following the application of Bio-algeen S90, the assimilation leaf area was larger, on average, by $941 \mathrm{~cm}^{2}$ than the plants from the control object without a biostimulant, with a comparable weight of leaves.

Table 5. Weight of leaves and assimilation leaf area

\begin{tabular}{c|c|c|c|c|c|c|c|c}
\hline \multirow{2}{*}{ Type of biostimulant } & \multicolumn{7}{c|}{ Years } & \multicolumn{3}{c}{ Cultivar } & \multirow{2}{*}{ Mean } \\
\cline { 2 - 6 } & $\mathbf{2 0 1 2}$ & $\mathbf{2 0 1 3}$ & $\mathbf{2 0 1 4}$ & Denar & Lord & Miłek & \\
\hline \multicolumn{7}{c}{ Weight of leaves $(\mathbf{g})$} \\
\hline Without biostimulant & 250 & 171 & 282 & $221 \mathrm{a}$ & $204 \mathrm{~b}$ & $279 \mathrm{a}$ & $234 \mathrm{a}$ \\
Bio-algeen S90 & 246 & 177 & 305 & $243 \mathrm{a}$ & $250 \mathrm{a}$ & $235 \mathrm{~b}$ & $243 \mathrm{a}$ \\
Kelpak SL & 262 & 167 & 284 & $238 \mathrm{a}$ & $234 \mathrm{ab}$ & $241 \mathrm{~b}$ & $238 \mathrm{a}$ \\
HumiPlant & 256 & 159 & 276 & $238 \mathrm{a}$ & $202 \mathrm{~b}$ & $251 \mathrm{ab}$ & $230 \mathrm{a}$ \\
Mean & $254 \mathrm{~B}$ & $169 \mathrm{C}$ & $287 \mathrm{~A}$ & $235 \mathrm{AB}$ & $222 \mathrm{~B}$ & $251 \mathrm{~A}$ & \\
\hline \multicolumn{7}{|c|}{ Assimilation leaf area (cm $)$} \\
\hline Without biostimulant & $7131 \mathrm{~b}$ & $5411 \mathrm{~b}$ & $9438 \mathrm{~b}$ & $7214 \mathrm{a}$ & $6425 \mathrm{~b}$ & $8341 \mathrm{a}$ & $7327 \mathrm{~b}$ \\
Bio-algeen S90 & $7847 \mathrm{a}$ & $5746 \mathrm{ab}$ & $10379 \mathrm{a}$ & $8120 \mathrm{a}$ & $8008 \mathrm{a}$ & $7845 \mathrm{a}$ & $7991 \mathrm{a}$ \\
Kelpak SL & $7964 \mathrm{a}$ & $6035 \mathrm{a}$ & $9434 \mathrm{~b}$ & $7871 \mathrm{a}$ & $7636 \mathrm{ab}$ & $7926 \mathrm{a}$ & $7811 \mathrm{a}$ \\
HumiPlant & $7963 \mathrm{a}$ & $5947 \mathrm{ab}$ & $9170 \mathrm{~b}$ & $7592 \mathrm{a}$ & $6903 \mathrm{~b}$ & $8584 \mathrm{a}$ & $7693 \mathrm{a}$ \\
Mean & $7726 \mathrm{~B}$ & $5785 \mathrm{C}$ & $9605 \mathrm{~A}$ & $7699 \mathrm{~B}$ & $7243 \mathrm{C}$ & $8174 \mathrm{~A}$ & \\
\hline
\end{tabular}

Means within columns/rows followed by the same lowercase/uppercase letters do not differ significantly at $\mathrm{p} \leq 0.05$

The type of biostimulant applied had a greater effect on the weight and assimilation leaf area of 'Lord' than 'Denar' and 'Miłek' (Table 5). Following the application of Bio-algeen S90, the weight of 'Lord' leaves was higher by $46 \mathrm{~g}$, on average, and the assimilation leaf area was larger by $1583 \mathrm{~cm}^{2}$ as compared with the plants from the control object without biostimulant. The differences were highest in 2014 with a low air temperature and a heavy rainfall after the plant emergence.

Regardless of the biostimulant applied, the weight and the assimilation leaf area were higher for 'Miłek' than for 'Denar' and 'Lord'. The plant growth indices were highest in 2014 with the highest air temperature and a moderate rainfall at the end of May (Table 5). 


\section{Leaf weight ratio $(L W R)$ and leaf area ratio $(L A R)$}

The biostimulants used in the experiment had no significant effect on the LWR or LAR (Table 6). Following the application of biostimulants, the plant growth indices were similar to the control object without biostimulant.

Table 6. Leaf weight ratio (LWR) and leaf area ratio (LAR)

\begin{tabular}{|c|c|c|c|c|c|c|c|}
\hline \multirow{2}{*}{ Type of biostimulant } & \multicolumn{3}{|c|}{ Years } & \multicolumn{3}{|c|}{ Cultivar } & \multirow{2}{*}{ Mean } \\
\hline & 2012 & 2013 & 2014 & Denar & Lord & Milek & \\
\hline \multicolumn{8}{|c|}{ Leaf weight ratio $\left(\mathrm{g} \mathrm{g}^{-1}\right)$} \\
\hline Without biostimulant & 0.446 & 0.455 & 0.380 & 0.388 & 0.413 & 0.480 & $0.427 \mathrm{a}$ \\
\hline Bio-algeen S90 & 0.434 & 0.449 & 0.366 & 0.381 & 0.398 & 0.471 & $0.416 \mathrm{a}$ \\
\hline Kelpak SL & 0.435 & 0.480 & 0.403 & 0.409 & 0.407 & 0.503 & $0.440 \mathrm{a}$ \\
\hline HumiPlant & 0.450 & 0.469 & 0.387 & 0.407 & 0.405 & 0.494 & $0.435 \mathrm{a}$ \\
\hline Mean & $0.441 \mathrm{~A}$ & $0.463 \mathrm{~A}$ & $0.384 \mathrm{~B}$ & $0.396 \mathrm{~B}$ & $0.406 \mathrm{~B}$ & $0.487 \mathrm{~A}$ & \\
\hline \multicolumn{8}{|c|}{ Leaf area ratio $\left(\mathrm{cm}^{2} \mathrm{~g}^{-1}\right)$} \\
\hline Without biostimulant & 13.50 & 16.47 & 12.60 & 13.10 & 13.46 & 16.01 & $14.19 \mathrm{a}$ \\
\hline Bio-algeen S90 & 13.37 & 15.83 & 12.50 & 12.51 & 13.27 & 15.93 & $13.90 \mathrm{a}$ \\
\hline Kelpak SL & 12.72 & 17.51 & 13.41 & 13.63 & 13.16 & 16.85 & $14.55 \mathrm{a}$ \\
\hline HumiPlant & 13.36 & 16.60 & 12.89 & 12.99 & 12.82 & 17.04 & $14.28 \mathrm{a}$ \\
\hline Mean & $13.24 \mathrm{~B}$ & $16.61 \mathrm{~A}$ & $12.85 \mathrm{C}$ & $13.06 \mathrm{~B}$ & $13.18 \mathrm{~B}$ & $16.46 \mathrm{~A}$ & \\
\hline
\end{tabular}

Means within columns/rows followed by the same lowercase/uppercase letters do not differ significantly at $\mathrm{p} \leq 0.05$

The LWR and LAR depended on the cultivar and weather conditions during potato growth (Table 6). Regardless of the treatment (with or without biostimulant), the LWR and LAR were higher for 'Miłek' than for 'Denar' and 'Lord'. The plant growth indices were lowest in 2014 with the highest air temperature and a moderate rainfall in the second half of May.

\section{Marketable tuber yield}

The productive effects of biostimulants used in the experiment were comparable, which was reflected in an increase in the marketable tuber yield in comparison with the cultivation without biostimulant (Table 7). In the three years of the study, the marketable tuber yield was higher by $2.15 \mathrm{t} \mathrm{ha}^{-1}$, on average. The yield-increasing effect of biostimulants depended on weather conditions during the potato growing season.

Table 7. Marketable tuber yield $\left(t \mathrm{ha}^{-1}\right)$

\begin{tabular}{c|c|c|c|c|c|c|c}
\hline \multirow{2}{*}{ Type of biostimulant } & \multicolumn{3}{|c|}{ Years } & \multicolumn{3}{c|}{ Cultivar } & \multirow{2}{*}{ Mean } \\
\cline { 2 - 7 } & $\mathbf{2 0 1 2}$ & $\mathbf{2 0 1 3}$ & $\mathbf{2 0 1 4}$ & Denar & Lord & Milek & \\
\hline Without biostimulant & $39.49 \mathrm{a}$ & $29.75 \mathrm{~b}$ & $29.34 \mathrm{~b}$ & 31.84 & 33.10 & 33.64 & $32.86 \mathrm{~b}$ \\
Bio-algeen S90 & $38.96 \mathrm{a}$ & $34.64 \mathrm{a}$ & $30.62 \mathrm{~b}$ & 34.49 & 35.47 & 34.26 & $34.74 \mathrm{ab}$ \\
Kelpak SL & $40.22 \mathrm{a}$ & $34.12 \mathrm{a}$ & $30.62 \mathrm{~b}$ & 33.50 & 35.46 & 36.00 & $34.99 \mathrm{a}$ \\
HumiPlant & $41.43 \mathrm{a}$ & $31.61 \mathrm{ab}$ & $32.83 \mathrm{a}$ & 34.95 & 36.21 & 34.71 & $35.29 \mathrm{a}$ \\
Mean & $40.02 \mathrm{~A}$ & $32.53 \mathrm{~B}$ & $30.86 \mathrm{C}$ & $33.69 \mathrm{~A}$ & $35.06 \mathrm{~A}$ & $34.65 \mathrm{~A}$ & \\
\hline
\end{tabular}

Means within columns/rows followed by the same lowercase/uppercase letters do not differ significantly at $\mathrm{p} \leq 0.05$ 
Bio-algeen S90 and Kelpak SL caused the highest increase in marketable tuber yield in the warm and very wet growing season of 2013. With the use of those biostimulants, the marketable tuber yield was higher by $4.63 \mathrm{t} \mathrm{ha}^{-1}$, on average, in comparison with the cultivation without biostimulant. HumiPlant caused the highest increase in marketable tuber yield in 2014 with a low air temperature and, at the same time, insufficient water supply for plants in the period of tuber growth. In that year, following the application of HumiPlant the marketable tuber yield was higher by $3.49 \mathrm{t} \mathrm{ha}^{-1}$. The type of biostimulant and cultivar interaction effect on marketable tuber yield was not statistically confirmed.

The marketable tuber yields of the tested potato cultivars were similar (Table 7). The yield of early potato was highest in the warm and moderately wet growing season of 2012.

\section{Discussion}

An analysis of plant growth is important to determine the effect of biostimulants on the crop yielding. In the present study, the type of biostimulant applied significantly affected the growth of very early potato cultivars. A faster rate of plant growth was observed with the use of seaweed extracts, than with the use of humic and fulvic acids. Seaweed extracts have more biostimulant potential due to the presence of phytohormones and a number of other compounds promoting plant growth and strengthening stress resistance (Begum et al., 2018). Among the tested seaweed extracts, Bio-algeen S90 (Ascophyllum nodosum) had a greater effect on the rate of plant growth than Keplak SL (Ecklonia maxima). Bio-algen S90 have more bioactive compounds than Kelpak SL. Following the Bio-algeen S90 application, the plants were higher and produced a greater above-ground biomass. The positive effect of the foliar application of Ascophyllum nodosum extract on the growth of medium-early potato cultivar was also shown in a study carried out in Pakistan (Haider et al., 2012). Following the application of HumiPlant, plants were lower but had a similar weight of stems as in the cultivation without biostimulant, which suggests that the stems were thicker. To date studies showed a generally positive effect of humic acids on potato growth. A study carried out in Iraq and Saudi Arabia showed that the application of humic acid promoted the growth of medium-early potato cultivars (Sarhan, 2011; Alenazi et al., 2016), whereas the results of a study carried out in Korea showed that foliar or soil application of humic and fulvic acids had no clear effect on the growth of medium-early potato cultivar (Suh et al., 2014). A study carried out in China showed that foliar application of fulvic acid increased the stem length and diameter of early potato cultivar and prolonged the plant growth period (Zhang et al., 2017), which was no clear confirmed in the present study. Plant response to exogenously applied humic substances depends on the plant species and its ontogeny and environment conditions. Plant growth response to humic substances obtained from leonardite are less than the response to humic substances obtained from peat, composts or vermicomposts (Canellas and Olivares, 2014). Biostimulants had no effect on the weight of leaves, but caused enlargement of the assimilation leaf area under abiotic stress conditions. In the year with the highest air temperature and a heavy rainfall after plant emergence, the assimilation leaf area was the largest after the application of Kelpak SL, whereas in the year with a lowest air temperature and with a heavy rainfall after plant emergence, the assimilation leaf area was the largest after the application of Bio-algeen S90. 
Biostimulants caused enlargement of the assimilation leaf area, but had no significant effect on the share of assimilation organs in the whole plant weight (LWR) or on the weight per unit leaf area (LAR). These indices are determined by the cultivar and plant growth stage, and by the interaction effect between the cultivar and environment (Pietkiewicz, 1985; Lahlou et al., 2003; Wadas and Kalinowski, 2017), which was confirmed in the present study. The LWR and LAR varied with plant growth, due to potato response to weather changes by falling or new growth of leaves (Pietkiewicz, 1985; Camargo et al., 2015).

The yield-increasing effect of biostomulants depended on the hydrothermal conditions during potato growth. The seaweed extracts Bio-algeen S90 and Kelpak SL produced better results in a warm and a very wet growing season. With the use of those biostimulants, the marketable tuber yield (with diameter above $30 \mathrm{~mm}$ ) was higher by $15.5 \%$ in comparison with the cultivation without biostimulant. Seaweed extracts improve the thermal tolerance of plants (Battacharyya et al., 2015), which was confirmed in the present study. Humic and fulvic acids from leonardite produced better results in a cool growing season and with insufficient water supply for plants in a period of tuber growth. With the use of HumiPlant the marketable tuber yield was higher by $12 \%$. Very early potato cultivars showed a differential response to seaweed extracts. Kelpak SL did not have a significant effect on the marketable tuber yield of very early potato cultivar 'Felka', but caused an increase in the yield of very early cultivar 'Volumia'. In a year with a lower air temperature and less rainfall, Bio-algeen S90 caused a higher increase in the total yield of the very early potato cultivar 'Volumia' than Kelpak SL (Erlichowski and Pawińska, 2003; Wierzbowska et al., 2015). Kelpak SL caused an increase in the total tuber yield of medium-early potato cultivars (Matysiak and Adamczewski, 2010). Kelpak SL contains auxins and cytokinins at the level of 350/1. Exogenous auxin plays an important role in tuber formation and plant stress resistance; however, the action of exogenous auxin depends on its concentration and light conditions. The potato growth response to exogenous auxin depends on the plant genotype and carbohydrate status (Kolachevskaya et al., 2019). Cytokinins also have an important effect of plant adaptation to environmental stresses. Under drought conditions, exogenous cytokinins can increase stomatal apertures and transpiration in plant, and have a positive effect on photosynthetic activity (Ha et al., 2012). In the present study, the type of biostimulant and cultivar interaction effect of early crop potato yield was not statistically confirmed. Positive potato response to humic substances originating from leonardite applied to soil or foliar was confirmed in studies carried out by other authors (Verlinden et al., 2009; Matysiak and Adamczewski, 2010). Under water stress, foliar application of humic acids increased leaf water retention and photosynthetic and antioxidant metabolism (Fahramand et al., 2014). Periods of high temperature and drought are becoming more frequent in Central Europe. In east-central Poland, the shortage of rainfall in the growing season of early potato cultivars occurs more often than their excess (Radzka et al., 2015).

A positive correlation was found between the tuber yield and the number of main stems per plant, stem length and diameter (Arslan, 2007; Darabad, 2014). A significant relationship was also found between the tuber yield and LWR and LAR (Zrüst and Čepl, 1991; Wadas and Kalinowski, 2017). In the present study, following the application of Bio-algeen S90, the plants were higher and produced a greater aboveground biomass than in the cultivation without biostimulant, whereas following the application of HumiPlant the stems were shorter at a similar weight as the control 
plants, which suggests that the stems were thicker. Biostimulants caused enlargement of the assimilation leaf area, but had no effect on the weight of leaves. This suggests that the leaves were thinner following the application of biostimulants. As the result, the biostimulants had no significant effect on the LWR or LAR. It often happens that the enlargement of the assimilation leaf area does not result in an increase in the tuber yield, because the rate of photosynthesis per unit of leaf area decreases with an increase in the leaf area (Pietkiewicz, 1985).

\section{Conclusions}

This study showed the possibility of improving plant growth in an early crop potato culture with the foliar application of seaweed extracts Ascophyllum nodosum (Bioalgeen S90) and Ecklonia maxima (Kelpak SL) and humic and fulvic acids from leonardite (HumiPlant). Seaweed extracts caused a faster rate of potato growth. Bioalgeen S90 had a greater effect on plant growth than Kelpak SL. Following the application of Bio-algeen S90, the plants were higher and produced a greater aboveground biomass than in the cultivation without biostimulant. Following the application of HumiPlant, plants were lower but had a similar weight of stems as plants in the cultivation without biostimulant. This suggests that the stems were thicker. Biostimulants caused enlargement of assimilation leaf area, but had no effect on the weight of leaves, which suggests that the leaves were thinner. As a results, the biostimulants had no effect on the leaf weight ratio (LWR) or leaf area ratio (LAR). The biostimulants caused an increase in the marketable tuber yield of early crop potato. The yield-increasing effect of biostimulants depended on the hydrothermal conditions during potato growth. Seaweed extracts produced better results in a warm and a very wet growing season, whereas humic and fulvic acids produced better results in a cool growing season and with a drought in the period of tuber growth. To use humic substances and seaweed extract for promoting plant growth in early crop potato culture, it is necessary to optimize their source and concentration for environmental conditions to achieve the expected outputs.

Acknowledgements. This study was supported by the Polish Ministry of Science and Higher Education under the statutory activities of the Siedlce University of Natural Sciences and Humanities (grant number 218/05/S).

\section{REFERENCES}

[1] Alenazi, M., Wahb-Allah, M. A., Abdel-Razzak, H. S., Ibrahim, A. A., Alsadon, A. (2016): Water regimes and humic acid application influences potato growth, yield, tuber quality and water use efficiency. - American Journal of Potato Research 93(5): 463-473. https://doi.org/10.1007/s12230-016-9523-7.

[2] Arslan, B. (2007): Relationships among yield and some yield characters in potato $(S$. tuberosum L.). - Journal of Biological Sciences 7(6): 973-976. https://doi.org/10.3923/jbs.2007.973.976.

[3] Battacharyya, D., Babgohari, M. Z., Rathor, P., Prithiviraj, B. (2015): Seaweed extracts as biostimulants in horticulture. - Scientia Horticulturae 196: 39-48. https://doi.org/10.1016/j.scienta.2015.09.012. 
[4] Begum, M., Bordoloi, B. C., Singha, D. D., Ojha, N. J. (2018): Role of seaweed extract on growth, yield and quality of some agricultural crops: A review. - Agricultural Reviews 39(4): 321-326. https://doi.org/10.18805/ag.r-1838.

[5] Bulgari, R., Cocetta, G., Trivellini, A., Vernieri, P., Ferrante, A. (2015): Biostimulants and crop response: a review. - Biological Agriculture and Horticulture 31(1): 1-17. https://doi.org/10.1080/01448765.2014.964649.

[6] Calvo, P., Nelson, L., Kloepper, J. W. (2014): Agricultural uses of plant biostimulants. Plant and Soil 383(1-2): 3-41. https://doi.org/10.1007/s11104-014-2131-8.

[7] Camargo, D. C., Montoya, F., Córcoles, J. I., Ortega, J. F. (2015): Modeling the impact of irrigation treatments on potato growth and development. - Agricultural and Water Management 150: 119-128. https://doi.org/10.1016/j.agwat.2014.11.017.

[8] Canellas, L. P., Olivares, F. L. (2014): Physiological responses to humic substances as plant growth promoter. - Chemical and Biological Technologies in Agriculture 1: 1-11. https://doi.org/10.1186/2196-5641-1-3.

[9] Canellas, L. P., Olivares, F. L., Aguiar, N. O., Jones, D. L., Nebbioso, A., Mazzei, P., Piccolo, A. (2015): Humic and fulvic acids as biostimulants in horticulture. - Scientia Horticulturae 196: 15-27. https://doi.org/10.1016/j.scienta.2015.09.013.

[10] Craige, J. S. (2011): Seaweed extract stimuli in plant science and agriculture. - Journal of Applied Phycology 23(3): 37-393. https://doi.org/10.1007/s10811-010-9560-4.

[11] Darabad, G. R. (2014): Study the relationships between yield and yield components of potato varieties using correlation analysis and regression analysis and causality. International Journal of Plant, Animal and Environmental Sciences 4(2): 584-589.

[12] Erlichowski, T., Pawińska, M. (2003): Biological evaluation of product Kelpak on potato plants. - Progress in Plant Protection 43(2): 606-609 (in Polish).

[13] Fahramand, M., Moradi, H., Noori, M., Sobhkhizi, A., Adibian, M., Abdollahi, S., Rigi, K. (2014): Influence of humic acid on increase yield of plants and soil properties. International Journal of Farming and Allied Science 3(3): 339-341.

[14] Ha, S., Vankova, R., Yamaguchi-Shinozaki, K., Shinozaki, K., Tran, L-S. P. (2012): Cytokinins: metabolism and function in plant adaptation to environmental stresses. Trends in Plant Science 17(3): 172-179. https://doi.org/10.1016/j.tplants.2011.12.005.

[15] Haider, M. W., Ayyub, C. M., Pervez, M. A., Asad, H. U., Manan, A., Raza, S. A., Ashraf, I. (2012): Impact of foliar application of seaweed extract on growth, yield and quality of potato (Solanum tuberosum L.). - Soil and Environment 31(2): 157-162.

[16] Kolachevskaya, O. O., Lomin, S. N., Arkhipov, D. V., Romanov, G. A. (2019): Auxin in potato: molecular aspects and emerging roles in tuber formation and stress resistance. Plant Cell Reports 38: 681-698. https://doi.org/10.1007/s00299-019-02395-0.

[17] Kuisma, P. (1989): The effect of foliar application of seaweed extract on potato. - Journal of Agricultural Science in Finland 61(5): 371-377. https://doi.org/10.23986/afsci.72367.

[18] Lahlou, O., Ouattar, S., Ledent, J. F. (2003): The effect of drought and cultivar on growth parameters, yield and yield components of potato. - Agronomie 23(3): 257-268. https://doi.org/10.1051/agro:2002089.

[19] Matysiak, K., Adamczewski, K. (2010): Effect of Moddus 250 EC, Kelpak SL, Algaminoplant, HumiPlant i Yield Plus on the size and structure of potato tuber yield. Ziemniak Polski 1: 28-32 (in Polish).

[20] Pietkiewicz, S. (1985): An indicator-based analysis of plant growth. - Wiadomości Botaniczne 29(1): 29-42 (in Polish).

[21] Prajapati, A., Patel, C. K., Singh, N., Jain, S. K., Chongtham, S. K., Maheshwari, M. N., Patel, C. R., Patel, R. N. (2016): Evaluation of seaweed extract on growth and yield of potato. - Environment and Ecology 34(2): 605-608.

[22] Radzka, E., Rymuza, K., Lenartowicz, T. (2015): Analysis of hydrothermal conditions and their impact on early potato yields. - Journal of Ecological Engineering 16(2): 120124. https://doi.org/10.12911/22998993/1866. 
[23] Sarhan, T. Z. (2011): Effect of humic acid and seaweed extracts on growth and yield of potato plant (Solanum tuberosum L.) Desiree cv. - Mesopotamia Journal of Agriculture 39(2): 19-27.

[24] Sharma, H. S. S., Fleming, C., Selby, C., Rao, J. R., Martin, T. (2014): Plant biostimulants: a review on the processing of macroalgae and use of extracts for crop management to reduce abiotic and biotic stresses. - Journal of Applied Phycology 26(1): 465-490. https://doi.org/10.1007/s10811-013-0101-9.

[25] Suh, H. Y., Yoo, K. S., Suh, S. G. (2014): Tuber growth and quality of potato (Solanum tuberosum L.) as affected by foliar or soil application of fulvic and humic acids. Horticulture Environment and Biotechnology 55(3): 183-189. https://doi.org/10.1007/s13580-014-0005-x.

[26] Verlinden, G., Pycke, J., Mertens, J., Debersaques, F., Verheyen, K., Baert, G., Bries, J., Haesaert, G. (2009): Application of humic substances results in consistent increases in crop yield and nutrient uptake. - Journal of Plant Nutrition 32(9): 1407-1426. https://doi.org/10.1080/01904160903092630.

[27] Wadas, W., Kalinowski, K. (2017): Effect of titanium on growth of very early-maturing potato cultivars. - Acta Scientiarum Polonorum, Hortorum Cultus 16(6): 125-138. https://doi.org/10.24326/asphc.2017.6.11.

[28] Wierzbowska, J., Cwalina-Ambroziak, B., Głosek-Sobieraj, M., Sienkiewicz, S. (2015): Effect of biostimulators on yield and selected chemical properties of potato tubers. Journal of Elementology 20(3): 757-768. https://doi.org/10.5601/jelem.2014.19.4.799.

[29] Zhang, Y., Zhou, Q., Li, Y., Xu, C., He, S., Huang, Y., Yang, H., Wang, M., Liu, L., Tang, M. (2017): Effect of fulvic acid on agronomic traits and yield of autumn potato. Agricultural Science and Technology 18(8): 1448-1451.

[30] Zrůst, J., Čepl, J. (1991): Dependence of early potato yield on some growth characteristics. - Rostlina Výroba 37: 925-933. 